\title{
Correction to: Exploring multi-level system factors facilitating educator training and implementation of evidence-based practices (EBP): a study protocol
}

Aubyn C. Stahmer ${ }^{1,3,4,5^{*}}$, Jessica Suhrheinrich ${ }^{2,5}$, Patricia L. Schetter ${ }^{1,4}$ and Elizabeth McGhee Hassrick ${ }^{6}$

\section{Correction}

After publication of the original article [1] it was brought to our attention that author Elizabeth McGhee Hassrick was erroneously included as Elizabeth McGee Hassrick. The correct spelling of the author's name is included in the author list of this Correction.

\begin{abstract}
Author details
'University of California, Davis MIND Institute, 2825 50th St, Sacramento, CA 95819, USA. ${ }^{2}$ College of Education, San Diego State University, 5500 Campanile Dr., San Diego, CA 92182, USA. ${ }^{3}$ Department of Psychiatry and Behavioral Sciences, University of California, Davis, Sacramento, USA. ${ }^{4}$ Center of Excellence in Developmental Disabilities, University of California, Davis, Sacramento, USA. ${ }^{5}$ Child and Adolescent Services Research Center, San Diego, USA. 'Life Course Outcomes Research Program at AJ Drexel Autism Institute, Drexel University, 3020 Market St, St 560, Philadelphia, PA 19104, USA.
\end{abstract}

Received: 16 April 2018 Accepted: 16 April 2018

Published online: 23 April 2018

\section{Reference}

1. Stahmer AC, et al. Exploring multi-level system factors facilitating educator training and implementation of evidence-based practices (EBP): a study protocol. Implement Sci. 2018;13:3. https://doi.org/10.1186/s13012-017-0698-1.

\footnotetext{
* Correspondence: astahmer@ucdavis.edu

${ }^{1}$ University of California, Davis MIND Institute, 2825 50th St, Sacramento, CA 95819, USA

${ }^{3}$ Department of Psychiatry and Behavioral Sciences, University of California, Davis, Sacramento, USA
} 